\title{
Article \\ Performance of Oleic Acid and Soybean Oil in the Preparation of Oil-in-Water Microemulsions for Encapsulating a Highly Hydrophobic Molecule
}

\author{
Laura Fernández-Peña ${ }^{1,2}$, Boutaina Z. El Mojahid ${ }^{1}$, Eduardo Guzmán ${ }^{1,3, * \mathbb{D}}$, Francisco Ortega ${ }^{1,3} \mathbb{D}$ \\ and Ramón G. Rubio $1,3, *$ (D) \\ 1 Departamento de Química Física, Facultad de Ciencias, Universidad Complutense de Madrid, Ciudad \\ Universitaria s/n, 28040 Madrid, Spain; laura.fernandez.pena@ucm.es (L.F.-P.); bzbirta@ucm.es (B.Z.E.M.); \\ fortega@quim.ucm.es (F.O.) \\ 2 Instituto Pluridisciplinar, Universidad Complutense de Madrid, Paseo Juan XXIII, 1, 28040 Madrid, Spain \\ 3 Centro de Espectroscopía y Correlación, Universidad Complutense de Madrid, Ciudad Universitaria s/n, \\ 28040 Madrid, Spain \\ * Correspondence: eduardogs@quim.ucm.es (E.G.); rgrubio@quim.ucm.es (R.G.R.)
}

\section{check for}

updates

Citation: Fernández-Peña, L.; Mojahid, B.Z.E.; Guzmán, E.; Ortega, F.; Rubio, R.G. Performance of Oleic Acid and Soybean Oil in the Preparation of Oil-in-Water Microemulsions for Encapsulating a Highly Hydrophobic Molecule. Colloids Interfaces 2021, 5, 50. https: / / doi.org/10.3390/ colloids5040050

Academic Editor: Victor Starov

Received: 29 October 2021

Accepted: 18 November 2021

Published: 22 November 2021

Publisher's Note: MDPI stays neutral with regard to jurisdictional claims in published maps and institutional affiliations.

Copyright: (c) 2021 by the authors. Licensee MDPI, Basel, Switzerland. This article is an open access article distributed under the terms and conditions of the Creative Commons Attribution (CC BY) license (https:// creativecommons.org/licenses/by/ $4.0 /)$.

\begin{abstract}
This work analyzes the dispersion of a highly hydrophobic molecule, (9Z)-N-(1,3-dihydroxy octadecan-2-yl)octadec-9-enamide (ceramide-like molecule), with cosmetic and pharmaceutical interest, by exploiting oil-in-water microemulsions. Two different oils, oleic acid and soybean oil, were tested as an oil phase while mixtures of laureth-5-carboxylic acid (Akypo) and 2-propanol were used for the stabilization of the dispersions. This allowed us to obtain stable aqueous-based formulations with a relatively reduced content of oily phase (around $3 \% w / w$ ), that may enhance the bioavailability of this molecule by its solubilization in nanometric oil droplets (with a size range of $30-80 \mathrm{~nm}$ ), that allow the incorporation of a ceramide-like molecule of up to $3 \% w / w$, to remain stable for more than a year. The nanometric size of the droplet containing the active ingredient and the stability of the formulations provide the basis for evaluating the efficiency of microemulsions in preparing formulations to enhance the distribution and availability of ceramide-like molecules, helping to reach targets in cosmetic and pharmaceutical formulations.
\end{abstract}

Keywords: ceramide; colloidal carriers; cosmetics; drug delivery; formulations; pharmaceutical products

\section{Introduction}

Encapsulation is a widespread option for increasing the availability of poorly watersoluble molecules to facilitate their incorporation in products with a technological and commercial interest [1-3]. Most of the currently used strategies for such purposes rely on the use of colloidal carriers [4-7], e.g., solubilization in micellar environments and encapsulation by emulsion-like dispersions, including nano- and micro-emulsions, or liposomes [8-12]. This is possible because colloidal carriers provide a favorable environment for the dispersion of the target molecules, protecting them against degradation, which contributes to obtaining more stable formulations [13-16]. Furthermore, the use of well-sketched encapsulation matrices can help in a controlled release of the active molecules $[17,18]$. These previously mentioned aspects have stimulated intense research activity for exploiting the nanodroplets of oil-in-water microemulsions $(\mathrm{O} / \mathrm{W})$ as suitable platforms for encapsulation, facilitating distribution in an aqueous environment, delivering hydrophobic substances, e.g., vitamins, anticancer drugs, or pigments, among other types of molecules [19-21], and providing the bases for the fabrication of formulations for multiple interested industries, including biomedical, food, and cosmetics [22-28].

$\mathrm{O} / \mathrm{W}$ microemulsions combine their easy preparation and thermodynamically stability with a high power for solubilizing hydrophobic components and enhancing their 
bioavailability $[29,30]$. Recently, Rahdar et al. [19] demonstrated that O/W microemulsions loaded with doxorubicin may be exploited to enhance the cytotoxicity of anticancer drugs. However, the use of this type of formulation does not contribute to the reduction of the drug toxicity against healthy cells. This discovery is in contrast with the findings by Sargazi et al. [31] in relation to the antitumoral effect of valproic acid. They reported that the encapsulation of such a compound using $\mathrm{O} / \mathrm{W}$ microemulsions leads to a sustained release of the drug, which contributes to a stronger inhibition of the proliferation of cancer cells relative to the free drug and reduces its effect on healthy cells. In another study, Aboudzadeh et al. [20] showed that the encapsulation of $\alpha$-tocopherol in $\mathrm{O} / \mathrm{W}$ microemulsions enhances its anti-oxidant activity relative to the free form due to a slow release of the active molecule from the microemulsions. This agrees with the findings by Hasanein et al. [32] in relation to the power of $\mathrm{O} / \mathrm{W}$ microemulsions containing spironolactone for preventing ischemia/reperfusion-induced renal injuries, which was ascribed to the enhanced drug bioavailability and delivery. The above discussion evidences the potential interest in the use of $\mathrm{O} / \mathrm{W}$ microemulsions for the encapsulation and delivery of active hydrophobic substances. However, a practical design of a suitable $\mathrm{O} / \mathrm{W}$ microemulsion for a specific application requires a careful choice of the components, i.e., surfactant, co-surfactant, and oil phases, used for containing the hydrophobic molecule, as well as the composition of each component. Furthermore, the most suitable preparation scheme for an $\mathrm{O} / \mathrm{W}$ microemulsion may change depending on the storage and application conditions, even for microemulsions encapsulating the same molecule. Therefore, the preparation of $\mathrm{O} / \mathrm{W}$ microemulsions requires a careful experimental design to ensure the optimal conditions for their preparation [33-35].

This work attempts to exploit the use of $\mathrm{O} / \mathrm{W}$ microemulsions as a platform for the encapsulation and delivery of a highly hydrophobic molecule that may be used for several cosmetic and therapeutic purposes: (9Z)-N-(1,3-dihydroxyoctadecan-2-yl)octadec-9-enamide (a ceramide-like molecule) shown in Figure 1. This molecule may be considered a synthetic analogous to the main ceramide existing in human tissues and organs that plays a very central role in several physiological processes, e.g., modulation of skin homeostasis [36,37], enhancement of cellular membrane permeability [38,39], and apoptosis [40]. Furthermore, dysfunctions on the metabolic pathways related to the biosynthesis of ceramides may be a signature of obesity-related diseases, e.g., type 2 diabetes, mellitus, or atherosclerosis [41,42]. Additionally, dysregulated ceramide metabolism may also be associated with the emergence of different types of tumors [43,44].<smiles>CCCCCCCC/C=C\CCCCCCCCCCCCC(=O)NC(CO)C(O)CO</smiles>

Figure 1. Scheme of the molecular structure of (9Z)-N-(1,3-dihydroxyoctadecan-2-yl)octadec-9enamide (a ceramide-like molecule).

For a long time, the most common approach in cosmetics and therapy has been focusing on the external stimulation of ceramide production $[45,46]$. However, interest is turning towards the design of cosmetic and pharmaceutical formulations to provide a direct exogenously delivery of ceramide-like molecules, which may contribute to the mitigation of physiological dysfunctions associated with ceramide production, and in particular, for the regulation of cellular stress, proliferation, senescence, and death [47-49]. Nevertheless, the exploitation of ceramide-like molecules in cosmetic or therapeutic products is limited by their high hydrophobicity and their hemolytic character, which makes it necessary to seek new alternatives for including these types of molecules in simple formulations with long-term stability so their efficacy can be maximized while their adverse effects are minimized [25,50]. This is possible by the use of liposomes, which allow selective targeting 
of the ceramide-like molecule to the cancer cells, reducing the side effect on healthy cells and tissues [51,52]. The use of liposomes containing ceramide has also been proven as an efficient alternative for repairing a disrupted skin barrier [53]. Another alternative carrier of ceramides are polymeric particles [54], however, $\mathrm{O} / \mathrm{W}$ nanoemulsions and microemulsions have emerged as the most suitable carriers for ensuring high efficiency in the encapsulation of ceramide-like molecules [12,36,55-57]. Therefore, the incorporation of ceramide-like molecules within the oil droplets of $\mathrm{O} / \mathrm{W}$ microemulsions containing a high-water content appears to be a viable alternative for ensuring the stabilization of the active molecules and contributes to its dispersion, creating a more convenient application. The high aqueous content of these formulations may favor their dispersion within cosmetic substrates, e.g., the skin, and within the bloodstream.

\section{Materials and Methods}

\subsection{Materials}

Oleic acid (purity $>99 \%$ ) supplied from Sigma-Aldrich (Saint Louis, MO, USA) and soybean oil (purity $>99 \%$ ) supplied from Alfa Aesar (Haverhill, MA, USA) were used as oil phases. The stabilization of microemulsions was attained by combining laureth-5-carboxylic acid (hereinafter Akypo, KAO Chemicals Europe, Barcelona, Spain) as the surfactant, and 2-propanol (HPLC grade, Sigma-Aldrich, Saint Louis, MO, USA) as the co-surfactant. The hydrophobic compound to be encapsulated was (9Z)-N-(1,3dihydroxyoctadecan-2-yl)octadec-9-enamide (hereinafter, ceramide-R) supplied by Avanti Polar Lipids, Ltd. (Alabaster, AL, USA).

The cleaning of the material and the sample preparation was done with ultrapure deionized water obtained from a multi-cartridge purification system aquaMAX ${ }^{\mathrm{TM}}$-Ultra 370 Series (Young Lin Instrument, Co., Gyeonggi-do, Korea). This water presented a resistivity higher than $18 \mathrm{M} \Omega \cdot \mathrm{cm}$, and a total organic content lower than $6 \mathrm{ppm}$.

\subsection{Preparation of $O / W$ Microemulsions}

$\mathrm{O} / \mathrm{W}$ microemulsions were prepared by weighing the required amounts of the different components with an analytical balance with a precision of $\pm 0.1 \mathrm{mg}$ to obtain mixtures with the desired compositions. For this purpose, a protocol adapted from our previous publication was followed [33]. The order of the addition of the different components to the mixture plays a key role in the efficient incorporation of the ceramide-like molecule into the formulation. The protocol used for the preparation of the $\mathrm{O} / \mathrm{W}$ microemulsions can be summarized as follows: first, the required amount of oil (oleic acid or soybean oil) was weighed and poured into a vial to obtain final mixtures with an oil content of $3 \% w / w$. Secondly, the required amount of 2-propanol was weighed and added to the oil, and the mixture homogenized for $5 \mathrm{~min}$ using a magnetic stirrer (500 rpm). Once the oil phase was ready, the required amount of a stock solution of Akypo was poured into the vial, and the obtained mixture diluted by the addition of water. Finally, the obtained mixture was homogenized by stirring (1000 rpm) for $10 \mathrm{~min}$ and left overnight to rule out the emergence of phase separation for stabilization.

The ceramide-load molecule was included during the second step of the preparation procedure dissolved in 2-propanol, i.e., a solution of ceramide-like molecule in 2-propanol was mixed with the oil phase, and then the rest of the components were added to the mixture following the same protocol followed in the preparation of the bare $\mathrm{O} / \mathrm{W}$ microemulsions. The preparation, characterization, and storage of both bare $\mathrm{O} / \mathrm{W}$ microemulsions and formulations loading the ceramide-like molecule were done at $25^{\circ} \mathrm{C}$.

The goal of this work was the optimization of $\mathrm{O} / \mathrm{W}$ microemulsions to encapsulate a ceramide-like molecule and to obtain a stable formulation with relevance to the cosmetic and pharmaceutical industries. This has required modulating the composition of both the emulsifier mixture formed by a surfactant, laureth-5-carboxylic acid, and a co-surfactant, 2-propanol, and the nature of the carrier oil. Two different natural oils have been tested (oleic acid and soybean oil), to discover the most favorable conditions for obtaining $\mathrm{O} / \mathrm{W}$ 
microemulsions and the incorporation of higher amounts of a ceramide-like molecule within the final formulation. This is important because the oil can contribute to the penetration of the formulation containing ceramide-like molecules through lipid membranes by modifying their elasticity and hydration $[58,59]$. In this study, a fixed amount of oil of $3 \% w / w$ was used in the preparation of the $\mathrm{O} / \mathrm{W}$ microemulsions. This value was fixed because the results of a previous study indicated that this concentration is enough to ensure good solubilization of hydrophobic substances within the oil core of $\mathrm{O} / \mathrm{W} \mathrm{mi-}$ croemulsions [33]. Additionally, the minimization of the oil content for the formulations is important to different aspects of the formulations, including the reduction of oil-induced dermal irritation [60,61] and the oily character of the formulations [62]. The control of these aspects is a very important issue for the consumer perception of the formulation.

\subsection{Evaluation of the Formation of $\mathrm{O} / \mathrm{W}$ Microemulsion}

The determination of the boundary of the $\mathrm{O} / \mathrm{W}$ microemulsion region was evaluated at $25^{\circ} \mathrm{C}$ from the ternary pseudo-phase diagrams. For this purpose, the construction of the phase diagram at three different values of the surfactant/co-surfactant ratio, and a fixed oil content $(3 \% w / w)$ was done. Therefore, these diagrams corresponded to cuts of the whole phase, consistent with the water/Akypo/2-propanol/oil (oleic acid or soybean oil), for different values of the surfactant/co-surfactant ratio (Akypo/2-propanol) maintaining a constant oil phase composition (oleic acid or soybean) at $3 \% w / w$. Figure 2 reports the investigated compositional lines of fixed surfactant/co-surfactant ratio and their character on the cut of the pseudo-ternary phase diagram with a constant oil ratio $(3 \% w / w)$.
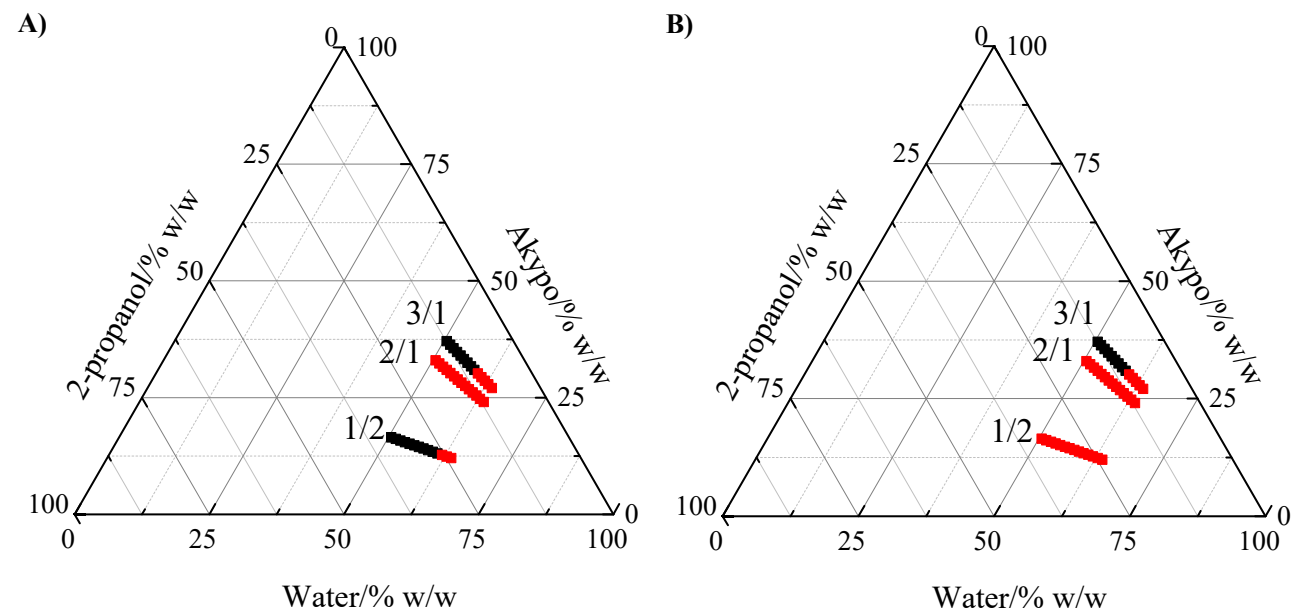

Figure 2. Cuts of the pseudo-ternary phase diagram corresponding to a fixed oil concentration $(3 \% w / w)$ showing the explored compositional lines of fixed surfactant/co-surfactant ratio (indicated in the diagrams) where the compositions corresponding to $\mathrm{O} / \mathrm{W}$ microemulsions $(\boldsymbol{\square})$ and phase-separated systems ( $\square$ ) are indicated with different colors. (A) Mixtures containing oleic acid. (B) Mixtures containing soybean oil.

$\mathrm{O} / \mathrm{W}$ microemulsions were identified as those dispersions that were transparent and stable according to visual inspection, i.e., they did not show any evidence of droplet aggregation and creaming, after more than six months.

\subsection{Dynamic Light Scattering}

Dynamic Light Scattering (DLS) performed with a Nanosizer ZS (Malvern instruments, Malvern, UK) was used for the characterization of the prepared microemulsions in terms of the apparent hydrodynamic diameter of the droplets [10,63-69]. DLS measurements were performed at $25^{\circ} \mathrm{C}$ in a quasi-backscattering configuration (scattering angle, $\theta=173^{\circ}$ ) using a He-Ne laser (wavelength, $\lambda=632 \mathrm{~nm}$ ). The DLS results were obtained as the 
average of five independent experiments consisting of ten measurements of $30 \mathrm{~s}$, with a standard deviation of less than $5 \%$ between independent measurements.

DLS provides information about the time dependence of the normalized intensity autocorrelation function, $g^{(2)}(q, t)$, which is described by a single exponential decay for dispersion of monodisperse scatters presenting Brownian motion [70]

$$
g^{(2)}(q, t)-1=\beta e^{-2 t / \tau},
$$

where $\tau$ is the characteristic Brownian decay time; $t$, in the usual case of polydisperse samples, is the average decay time; and $q=(4 \pi n / \lambda) \sin (\theta / 2)$ is the wave vector, with $n$ being the continuous phase refractive index $(n=1.33)$. In Equation (1), $\beta$ is the optical coherence factor, which in most general experimental conditions is close to 1 . The fitting of the intensity autocorrelation function (using the cumulant method or non-linear fitting) [70] allows for obtaining the apparent diffusion coefficient of the scatters $D_{\text {app }}=1 / \tau q^{2}$ for spherical objects diffusing in a continuous Newtonian medium that can be used for estimating the average size of the droplets as the apparent hydrodynamic diameter $\left(d_{a p p}^{h}\right)$ by the Stoke-Einstein relationship

$$
d_{a p p}^{h}=k_{B} T /\left(3 \pi \eta D_{a p p}\right)
$$

where $k_{B}$ and $T$ correspond to the Boltzmann constant and the absolute temperature, respectively.

\section{Results}

\subsection{Characterization of Bare Oil-in-Water Microemulsions}

The first step towards a practical design of $\mathrm{O} / \mathrm{W}$ microemulsions for enhancing the availability of poorly soluble molecules, such as ceramide-like molecules, is to find the compositional region which allows for obtaining stable dispersions with long term-stability. This means that is necessary to identify the stability region associated with the formation of $\mathrm{O} / \mathrm{W}$ microemulsions. For this purpose, the pseudo-ternary phase diagram of the system formed by water, oil, and the emulsifier (surfactant/co-surfactant mixture) was screened to find dispersions that can be identified as $\mathrm{O} / \mathrm{W}$ microemulsions. Considering the Akypo/2propanol mixture (surfactant/co-surfactant mixture) as a single component simplifies the analysis of the phase diagram, reducing the number of variables to explore. Thus, by changing the concentration of the emulsifier (Akypo/2-propanol mixture, cAkypo/2-propanol), for a fixed surfactant/co-surfactant ratio, it was possible to obtain the regions in which mono-phasic dispersions were obtained for systems containing a fixed amount of oil ( $3 \% w / w$ of oleic acid or soybean oil), i.e., the screened region is a cut of the true phase diagram at constant temperature $\left(25^{\circ} \mathrm{C}\right)$ and oil concentration $(3 \% w / w)$. Following previous studies for analogous systems [71,72], an Akypo/2-propanol ratio (S/CS ratio) of $3 / 1$ was initially fixed for obtaining stable $\mathrm{O} / \mathrm{W}$ microemulsions, and once the range of surfactant/co-surfactant concentrations was determined for the explored ratio (in the range of Akypo/2-propanol mixture concentrations of 40-48\% w/w), other Akypo/2-propanol ratios were then screened $(2 / 1$ and $1 / 2)$. It should be noted that the preparation of $\mathrm{O} / \mathrm{W}$ microemulsions with different concentrations of the mixture of Akypo and 2-propanol slightly modifies the water/oil ratio (WOR). Table 1 summarizes the range of compositions in which stable $\mathrm{O} / \mathrm{W}$ microemulsions were found for dispersions containing a fixed oil content (3\% $w / w$ of oleic acid or soybean oil) and surfactant/co-surfactant ratios. It should be noted that the modification of the latter may lead to the compositional range shifting for the formation of stable $\mathrm{O} / \mathrm{W}$ microemulsions, or the impossibility of their formation $(2 / 1$ for emulsions with both oils and $1 / 2$ using soybean oil as oil phase). 
Table 1. Summary of the compositional range for obtaining stable O/W microemulsions which may be tested for encapsulation purposes.

\begin{tabular}{cccc}
\hline Oil Phase & S/CS Ratio & WOR Range & $\begin{array}{c}c_{\text {Akypo/2-propanol Range for Stable O/W Microemulsions }} \\
(\% \text { w/w) }\end{array}$ \\
\hline \multirow{2}{*}{ Oleic acid } & $3 / 1$ & $19 / 1-17 / 1$ & $40-48$ \\
Soybean oil & $1 / 2$ & $20 / 1-17 / 1$ & $38-48$ \\
\hline
\end{tabular}

For mixtures containing an Akypo/2-propanol ratio of 3/1, it was possible to obtain $\mathrm{O} / \mathrm{W}$ microemulsions for mixtures with a total concentration of emulsifier (surfactant/cosurfactant mixture) in the range $40-48 \% w / w$, independently on the type of oil used. Notably, for concentrations of the surfactant/co-surfactant mixture below $40 \% w / w$, the dispersions undergo a fast phase separation. For surfactant concentrations higher than $48 \% w / w$, the surfactant/co-surfactant mixture becomes the main component of the dispersion, and hence it is not possible to define the dispersions as $\mathrm{O} / \mathrm{W}$ microemulsions. However, the results show that, regardless of the oil used, for mixtures with a ratio of Akypo/2-propanol of 2/1 it was not possible to obtain O/W microemulsions. This may be the result of the inefficiency of the surfactant/co-surfactant mixtures to effectively reduce the oil droplet/aqueous phase interfacial tension. If the 2-propanol concentration is increased in relation to that of Akypo (surfactant/co-surfactant ratio 2/1), the range of concentrations of the surfactant/co-surfactant mixture allowing the formation of $\mathrm{O} / \mathrm{W}$ microemulsions is enlarged to mixtures with a $3 / 1$ ratio $(38-48 \% w / w$ against $40-48 \% w / w)$ for dispersions including oleic acid in the oil phase. However, the formation of $\mathrm{O} / \mathrm{W}$ microemulsions is completely hindered when soybean oil is used in dispersions. This may be explained as a result of the partial incorporation of oil molecules into the interfacial layer, as was previously reported in the literature [73,74], which can provide additional stabilization to the dispersion. Thus, oleic acid, whose molecular size similar to a conventional surfactant, may play a surfactant role at the interface, contributing to the decrease of the surface tension and hence, to the stabilization of the $\mathrm{O} / \mathrm{W}$ microemulsions. In contrast, the large size of the triglyceride molecules that form soybean oil makes it difficult for their incorporation between the surfactant molecules at the oil droplet/aqueous phase interface [75].

The characterization of the stable $\mathrm{O} / \mathrm{W}$ microemulsions was performed in terms of the droplet size evaluated as related to the apparent hydrodynamic diameter obtained from DLS. Figure 3A shows the autocorrelation functions of intensities, and the respective intensity distributions obtained from the analysis of a set of three $\mathrm{O} / \mathrm{W}$ microemulsions with a fixed surfactant/co-surfactant ratio in which the concentration of the mixture of a stabilizing agent is fixed. This allows one to evaluate the effect of the emulsifier concentration (Akypo/2-propanol mixture) on the stabilization of the $\mathrm{O} / \mathrm{W}$ microemulsions. The results indicate that the dispersions have a mostly monomodal character with the intensity autocorrelation functions (see Figure 3A) decaying at long times, and appearing very similar independent of the composition of the mixture. On the other hand, the intensity distributions (see Figure $3 \mathrm{~B}$ ) indicate a rather monodisperse character, with a polydispersity index around 0.10 , independent of the $\mathrm{O} / \mathrm{W}$ microemulsion composition. This monodisperse character of the droplets allows the results to be discussed in terms of the average value of the apparent hydrodynamic diameter, referred to as a size. Furthermore, the characteristic decay time is shorter as the content of the emulsifier mixture (Akypo/2-propanol mixture) increases, which evidences the decrease of the droplet size and an increase of the dispersion stability. 

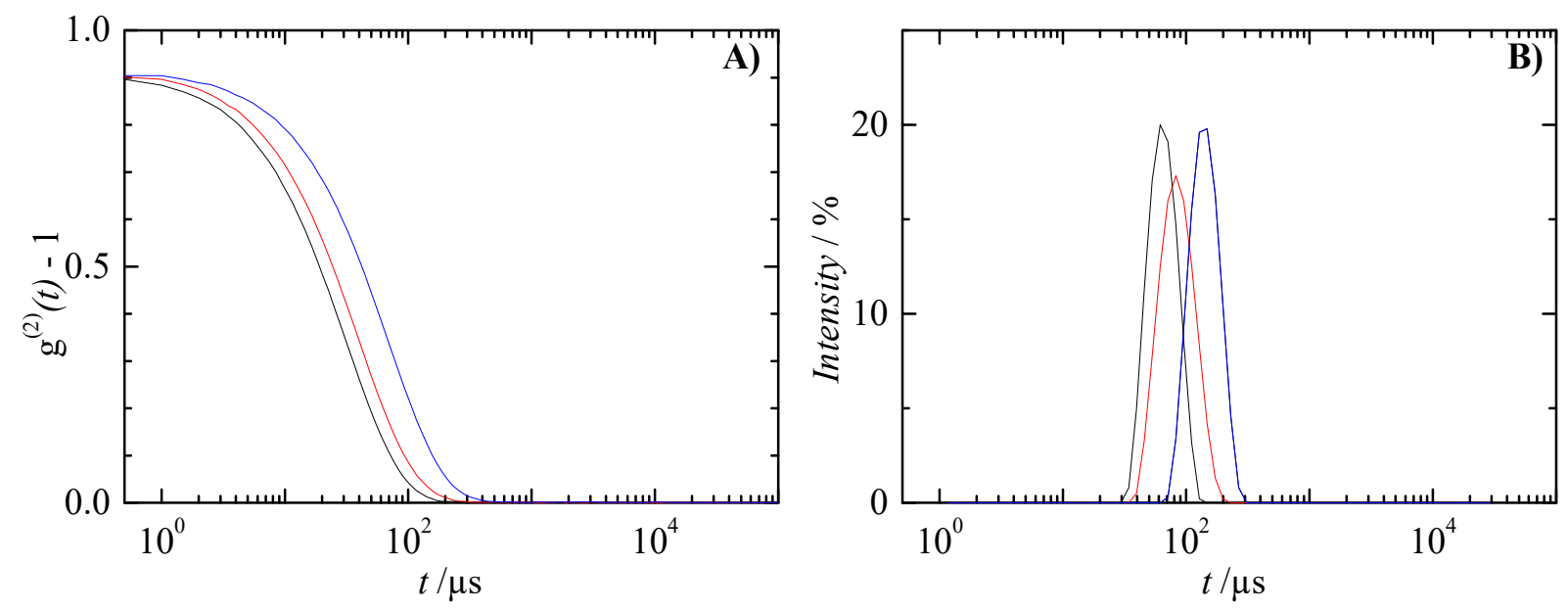

Figure 3. DLS study of different $\mathrm{O} / \mathrm{W}$ microemulsions with different emulsifier (surfactant/co-surfactant mixture) concentrations and a fixed Akypo/2-propanol ratio of 1/2 (the oil content remains constant at 3\% w/w): (A) Autocorrelation functions of intensities. (B) Intensity distributions. The different plots correspond to $\mathrm{O} / \mathrm{W}$ microemulsions with different concentrations of the surfactant/co-surfactant mixture: (-) $48 \% w / w,(-) 44 \% w / w$, and (-) $41 \% w / w$.

The analysis of the autocorrelation intensity functions allows for obtaining information on the apparent hydrodynamic diameter of the $\mathrm{O} / \mathrm{W}$ microemulsion droplets. Figure 4 reports the variation of the droplet size of $\mathrm{O} / \mathrm{W}$ microemulsions with the emulsifier (Akypo/2-propanol mixture) concentration for fixed values of the Akypo/2-propanol ratio. The results indicate that the droplet size range between 20 and $90 \mathrm{~nm}$, becomes smaller as the emulsifier concentration (Akypo/2-propanol mixture, $c_{\text {Akypo/2-propanol }}$ ) increases. Considering that one of the most critical parameters controlling the droplet size is the packing density of the stabilizing molecules at the oil droplet/aqueous phase interface, this can be easily explained. Thus, the higher the packing density of the interfacial film, the higher its stiffness, and the smaller the droplet size. This may be explained considering that the increase of the total concentration of the surfactant/co-surfactant mixture is associated with an enhanced reduction of the surface tension, favoring the formation of smaller droplets [76]. Furthermore, according to the thermodynamic picture for $\mathrm{O} / \mathrm{W}$ microemulsion stability, it may be supposed that for systems with the same oil content as those studied, the smaller the droplet size leads to a higher number of droplets, which increases the entropy, and consequently the stability of the dispersions.

The combination of the decrease in steric hindrance and the occurrence of cohesive forces between the surfactant and the oleic acid at the oil droplet/aqueous phase interface leads to the formation of the smallest droplets for dispersions containing a surfactant/cosurfactant ratio of $1 / 2$. Assuming that mixtures with an akypo/2-propanol ratio of 3/1, the high amount of surfactant (Akypo) favors the cohesive van der Waals interactions which enhances the stability of the dispersion. However, for dispersions with a surfactant/cosurfactant ratio of $1 / 2$ containing oleic acid (which presents a lower Akypo concentration) within the oil phase, the steric hindrance to the incorporation of oleic acid molecules into the interfacial film as the oil droplet/aqueous phase interface is reduced, and van der Waals interactions in the interfacial region may occur between the oleic acid and the hydrophobic tail of the Akypo, thus conferring high stability to the obtained dispersions. The incorporation of the oil is not possible in the case of mixtures with a surfactant/cosurfactant ratio of $1 / 2$ when soybean oil is used. This indicates the importance of steric hindrance in the control of the packing of interfacial film at the oil droplet/aqueous phase interface. Accordingly, the largesize of the soybean oil molecules limits the possibility of being placed in the interfacial region with the proper configuration to interact with Akypo molecules at the interface. 


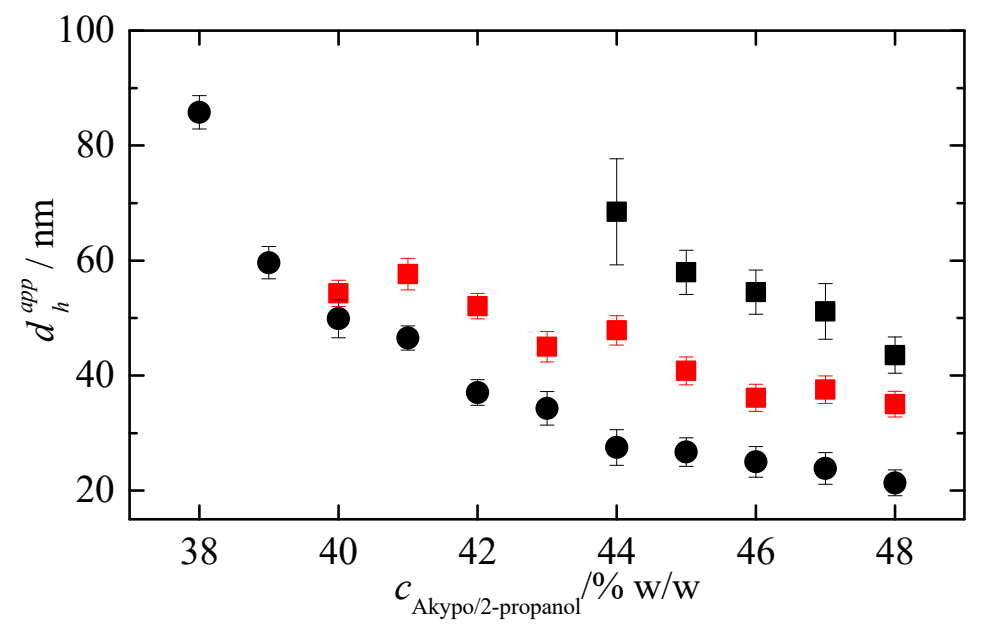

Figure 4. Dependence of the apparent hydrodynamic diameter on the concentration of emulsifiers (Akypo/2-propanol mixture, $c_{\text {Akypo/2-propanol }}$ ) for the studied $\mathrm{O} / \mathrm{W}$ microemulsions obtained in this study: (ם) O/W microemulsions with surfactant/co-surfactant mixture ratio 3/1 and oleic acid. (口) $\mathrm{O} / \mathrm{W}$ microemulsions with surfactant/co-surfactant mixture ratio $3 / 1$ and soybean oil. (•) $\mathrm{O} / \mathrm{W}$ microemulsions with surfactant/co-surfactant mixture ratio $1 / 2$ and oleic acid. The oil content in all the dispersions was $3 \% w / w$.

The impossibility of stabilizing $\mathrm{O} / \mathrm{W}$ microemulsions using a surfactant/co-surfactant ratio of $2 / 1$, independently of the oil used, can be justified considering that neither the concentration of surfactant is high enough to form rigid films, nor the amount of 2-propanol is high enough to decrease the steric hindrance to favor the incorporation of oil molecules at the interfacial region in such a way that promotes the formation of a strong cohesive interaction between surfactant and oil molecules [77].

Finally, it was found that for a fixed surfactant/co-surfactant ratio (3/1), the size of the droplets of $\mathrm{O} / \mathrm{W}$ microemulsions, including oleic acid in the oil phase, is relatively larger than those that are found for dispersions containing soybean oil, and therefore more susceptible to undergo coalescence and the subsequent creaming [78,79]. This is dependent on the characteristics of the interfacial film surrounding the individual droplets, in particular its stiffness, and the viscosity of the continuous fluid. Thus, assuming that the stiffness of the interfacial film for dispersions with surfactant/co-surfactant ratio of $3 / 1$ is identical, independent of the oil used, the only parameter that distinguishes both systems is the oil phase. The viscosity of the oleic acid is 0.6 times the viscosity of the soybean oil, which may favor a faster diffusion of the droplets leading to coalescence phenomena and consequently increasing the droplet size. Therefore, viscosity becomes another determining factor for obtaining $\mathrm{O} / \mathrm{W}$ microemulsions [80]. This also justifies the emergence of gel-like $\mathrm{O} / \mathrm{W}$ microemulsions due to the formation of a network of percolated droplets for dispersions including oleic acid within the oil phase and stabilized with surfactant/co-surfactant mixtures with concentrations ranging between $40 \%$ and $43 \% w / w$ and a fixed Akypo/2-propanol ratio (3/1) [81]. It should be noted that the high viscosity of the gel-like microemulsions leads to auto-correlation functions in which the Brownian fluctuations slow down which, combined with a loss of coherence due to the arrested motion of droplets, prevents the estimation of values of apparent hydrodynamic diameter for this type of microemulsions from DLS experiments [33].

\subsection{Inclusion of Ceramide-like Molecule in $\mathrm{O} / \mathrm{W}$ Microemulsions}

Once the compositional region in which it is possible to obtain $\mathrm{O} / \mathrm{W}$ microemulsions was defined, they were tested as platforms for the solubilization of the ceramide-like molecule. It is worth noting that the incorporation of an additional molecule within the formulation may modify the compositional region in which $\mathrm{O} / \mathrm{W}$ microemulsions are formed, or even completely hinder their formation. This highlights the importance of 
the adequate determination of the limit of the region in which $\mathrm{O} / \mathrm{W}$ microemulsions are obtained. Thus, the solubilization of the ceramide-like molecule was evaluated by selecting $\mathrm{O} / \mathrm{W}$ microemulsions with different surfactant/co-surfactant ratios, separated from the boundaries of the compositional range in which $\mathrm{O} / \mathrm{W}$ microemulsions were obtained, to prevent the inclusion of an additional component (ceramide-like molecule) leading to a catastrophic destabilization of the dispersion. Considering the above boundary condition, $\mathrm{O} / \mathrm{W}$ microemulsions with a total concentration of the surfactant/co-surfactant mixture of about $43-44 \% w / w$ were tested as platforms for ceramide-like molecule solubilization. Table 2 summarizes the compositions of the $\mathrm{O} / \mathrm{W}$ microemulsions used with the maximum amount of such molecules that can be solubilized before finding evidence of destabilization. The maximum amount of incorporated ceramide-like molecule in $\mathrm{O} / \mathrm{W}$ microemulsions with a specific composition without altering the dispersion stability was determined by analyzing independent samples of fixed composition with increasing amounts of the ceramide-like molecule. Thus, it is possible to determine the maximum content of a ceramide-like molecule that can be loaded in the $\mathrm{O} / \mathrm{W}$ microemulsions without an excess of insolubilized ceramide-like molecules appearing in the vial or the dispersion undergoing destabilization, i.e., the excess incorporation of ceramide-like molecules induces phase separation.

Table 2. Summary of the maximum amount of ceramide-like molecule that can be solubilized within $\mathrm{O} / \mathrm{W}$ microemulsions with fixed surfactant/co-surfactant ratio and concentration, and oil content of $3 \% w / w$.

\begin{tabular}{|c|c|c|c|c|}
\hline Oil Phase & Surfactant/Co-Surfactant Ratio & $\begin{array}{c}c_{\text {Akypo/2-propanol }} \\
(\% \text { w/w) }\end{array}$ & $\begin{array}{c}\text { Maximum Amount of Ceramide } \\
\qquad(\% w / w)\end{array}$ & Character \\
\hline \multirow{2}{*}{$\begin{array}{l}\text { Oleic acid } \\
\text { Soybean } \\
\text { oil }\end{array}$} & $3 / 1$ & 43 & 1 & Gel-like \\
\hline & $3 / 1$ & 43 & $\leq 2$ & Liquid \\
\hline Oleic acid & $1 / 2$ & 43 & $\leq 3$ & Liquid \\
\hline \multirow{2}{*}{$\begin{array}{l}\text { Oleic acid } \\
\text { Soybean } \\
\text { oil }\end{array}$} & $3 / 1$ & 44 & $\leq 2$ & Gel-like \\
\hline & $3 / 1$ & 44 & $\leq 2$ & Liquid \\
\hline Oleic acid & $1 / 2$ & 44 & $\leq 3$ & Liquid \\
\hline
\end{tabular}

The results show that the smaller the size of the $\mathrm{O} / \mathrm{W}$ microemulsion droplets and the higher their number, the higher the amount of ceramide-like molecules that can be solubilized within them, with the latter (in the range 1-3\% $w / w$ ) being dependent on the composition of the $\mathrm{O} / \mathrm{W}$ microemulsion used as a platform for the incorporation of the target molecule. Furthermore, the analysis of the appearance of the $\mathrm{O} / \mathrm{W}$ microemulsions allows for certain information to be obtained about the incorporation process of the ceramide-like molecule to the microemulsions. $\mathrm{O} / \mathrm{W}$ microemulsions with a composition closer to the boundary of the destabilization line, i.e., $\mathrm{O} / \mathrm{W}$ microemulsions containing oleic acid and a fixed surfactant/co-surfactant ratio of 3/1, present a gel-like character upon the incorporation of the ceramide-like molecule. This behavior may be correlated to an increase in the tendency of the droplets to coalesce, which appears reasonable considering that the incorporation of the ceramide-like molecule is associated with an increase of the volume of the dispersed phase, and hence the packing of the interfacial film is expected to be reduced with the incorporation of a ceramide-like molecule, favoring the coalescence of the droplets. This does not occur when the surfactant/co-surfactant ratio is $1 / 2$ because the oleic acid included within the oil droplets can likely diffuse to the interfacial region to compensate for the weakening of the interfacial packing emerging from the increase of the volume of the oil phase.

Figure 5 displays the dependence of the apparent hydrodynamic diameter of $\mathrm{O} / \mathrm{W}$ microemulsion droplets on the amount of ceramide-like molecule $\left(c_{\text {ceramide }}\right)$ for liquid-like $\mathrm{O} / \mathrm{W}$ microemulsions (see Table 2) with the two studied oils and two different values of the concentration of the Akypo/2-propanol mixture ( $43 \% w / w$ and $44 \% w / w$, respectively). 
As expected, the increase of the volume of the oil phase for a fixed amount of the emulsifier mixture results in the formation of bigger droplets, i.e., the results show an increase in droplet size with ceramide concentration, with an increase of the PDI. The latter assumes values slightly higher than 0.20 for the highest concentrations of the incorporated ceramidelike molecule, which indicates that the incorporation of the ceramide-like molecule into the oil reduces the size homogeneity of the droplets in relation to the bare emulsion. Furthermore, the incorporation of the ceramide-like molecule at a fixed concentration of the emulsifier mixture drives the dispersion to a new composition that is closer to the limit of the $\mathrm{O} / \mathrm{W}$ microemulsion region. Notably, the visual inspection of the $\mathrm{O} / \mathrm{W}$ microemulsions loaded with the ceramide-like molecule had no indication of droplet aggregation or creaming associated with the incorporation of the ceramide-like molecule after more than six months post preparation, evidence of the long-term stability of these formulations.

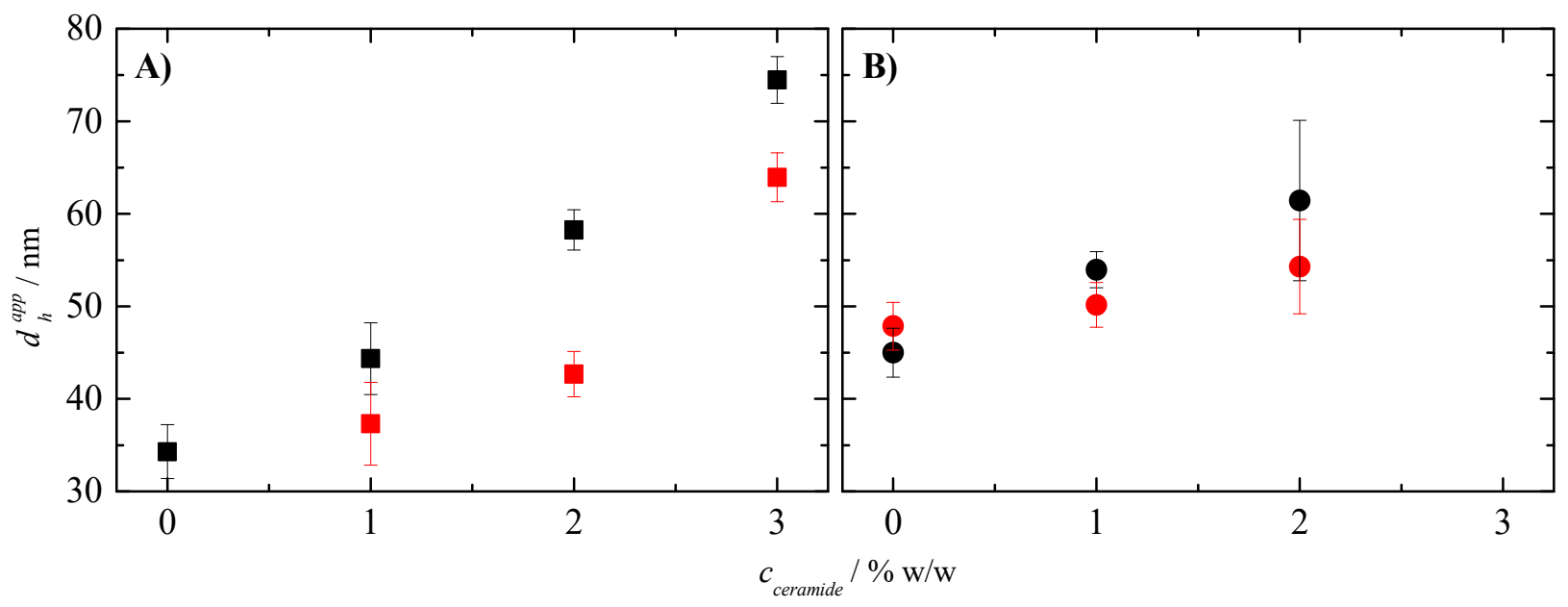

Figure 5. Dependence of apparent hydrodynamic diameter on the concentration of solubilized ceramide in the microemulsions obtained from DLS experiments. (A) O/W microemulsions with oleic acid in the oil phase and Akypo/2-propanol of a $1 / 2$ ratio with a total concentration of the emulsifier mixture of $(\boldsymbol{\square}) 43 \% w / w$ and (口) $44 \% w / w$. (B) O/W microemulsions with soybean in the oil phase and Akypo/2-propanol of a 1/2 ratio with a total concentration of the emulsifier mixture of (•) $43 \% w / w$ and $(\bullet) 44 \% w / w$. The oil content in all the dispersions was $3 \% w / w$.

\section{Conclusions}

This work focused on the practical design of suitable platforms for the dispersion of a highly hydrophobic molecule, (9Z)-N-(1,3-dihydroxyoctadecan-2-yl)octadec-9-enamide (a ceramide-like molecule), in an aqueous environment to enhance its bioavailability and facilitate its development in cosmetic and pharmaceutical formulations. This may be possible by using $\mathrm{O} / \mathrm{W}$ microemulsions stabilized by a mixture of laureth-5-carboxylic acid (Akypo) and 2-propanol in addition to one of two different oils (oleic acid and soybean) as an environment to include the hydrophobic molecule. The results indicate the possibility of exploiting $\mathrm{O} / \mathrm{W}$ microemulsions in a broad range of compositions for the dispersion of a ceramide-like molecule with an almost $3 \% w / w$. The type of oil, the surfactant/co-surfactant ratio, the total emulsifier concentration (Akypo+2-propanol), and the amount of the incorporated ceramide-like molecule play a very important role in controlling the properties of the formulations, especially the droplet size (in the range of $30-80 \mathrm{~nm}$ ). The most suitable formulations for solubilizing the ceramide-like molecule were $\mathrm{O} / \mathrm{W}$ microemulsions presenting compositions far from those expected from the onset of the phase separation region. This work has only analyzed the optimization of the solubilization efficiency of $\mathrm{O} / \mathrm{W}$ microemulsions for a ceramide-like molecule, however, the obtained results suggest that $\mathrm{O} / \mathrm{W}$ microemulsions may be a versatile tool for enhancing the distribution of hydrophobic molecules of cosmetic or pharmaceutical interest. 
Author Contributions: Conceptualization, E.G.; methodology, E.G., B.Z.E.M. and L.F.-P.; software, E.G.; validation, E.G., F.O. and R.G.R.; formal analysis, E.G. and L.F.-P.; investigation, E.G., L.F.-P., B.Z.E.M., F.O. and R.G.R.; resources, F.O. and R.G.R.; data curation, E.G. and L.F.-P.; writing—original draft preparation, E.G., L.F.-P. and B.Z.E.M.; writing-review and editing, E.G., L.F.-P., F.O. and R.G.R.; visualization, E.G. and L.F.-P.; supervision, E.G., L.F.-P. and R.G.R.; project administration, E.G., F.O. and R.G.R.; funding acquisition, E.G., F.O. and R.G.R. All authors have read and agreed to the published version of the manuscript.

Funding: This work was funded by MICINN under grant PID2019-106557GB-C21 and by The E.U. on the framework of the European Innovative Training Network-Marie Sklodowska-Curie Action NanoPaint (grant agreement 955612).

Institutional Review Board Statement: Not applicable.

Informed Consent Statement: Not applicable.

Data Availability Statement: Data are available upon request.

Acknowledgments: Centro de Espectroscopía y Correlación of Universidad Complutense de Madrid is acknowledged for its availability in the use of their facilities.

Conflicts of Interest: The authors declare no conflict of interest. The funders had no role in the design of the study; in the collection, analyses, or interpretation of data; in the writing of the manuscript; or in the decision to publish the results.

\section{References}

1. Gulyakin, I.D.; Oborotova, N.A.; Pechennikov, V.M. Solubilization of Hydrophobic Antitumor Drugs (Review). Pharm. Chem. J. 2014, 48, 209-213. [CrossRef]

2. Agrawal, A.G.; Kumar, A.; Gide, P.S. Toxicity Study of a Self-nanoemulsifying Drug Delivery System Containing N-methyl pyrrolidone. Drug Res. 2015, 65, 446-448. [CrossRef]

3. Sun, R.; Xia, N.; Xia, Q. Non-aqueous nanoemulsions as a new strategy for topical application of astaxanthin. J. Dispers. Sci. Technol. 2020, 41, 1777-1788. [CrossRef]

4. Lu, W.; Kelly, A.L.; Miao, S. Emulsion-based encapsulation and delivery systems for polyphenols. Trends Food Sci. Technol. 2016, 47, 1-9. [CrossRef]

5. Guimarães, K.L.; Ré, M.I. Lipid Nanoparticles as Carriers for Cosmetic Ingredients: The First (SLN) and the Second Generation (NLC). In Nanocosmetics and Nanomedicines: New Approaches for Skin Care; Beck, R., Guterres, S., Pohlmann, A., Eds.; Springer: Berlin/Heidelberg, Germany, 2011; pp. 101-122.

6. Lucia, A.; Argudo, P.G.; Guzmán, E.; Rubio, R.G.; Ortega, F. Formation of surfactant free microemulsions in the ternary system water/eugenol/ethanol. Colloids Surf. A 2017, 521, 133-140. [CrossRef]

7. Argudo, P.G.; Guzmán, E.; Lucia, A.; Rubio, R.G.; Ortega, F. Preparation and Application in Drug Storage and Delivery of Agarose Nanoparticles. Int. J. Polym. Sci. 2018, 2018, 7823587. [CrossRef]

8. Zhang, Y.; Song, W.; Geng, J.; Chitgupi, U.; Unsal, H.; Federizon, J.; Rzayev, J.; Sukumaran, D.K.; Alexandridis, P.; Lovell, J.F. Therapeutic surfactant-stripped frozen micelles. Nat. Commun. 2016, 7, 11649. [CrossRef]

9. Lucia, A.; Guzmán, E. Emulsions containing essential oils, their components or volatile semiochemicals as promising tools for insect pest and pathogen management. Adv. Colloid Interface Sci. 2021, 287, 102330. [CrossRef] [PubMed]

10. Cáceres, M.; Guzmán, E.; Alvarez-Costa, A.; Ortega, F.; Rubio, R.G.; Coviella, C.; Santo Orihuela, P.L.; Vassena, C.V.; Lucia, A. Surfactantless Emulsions Containing Eugenol for Imidacloprid Solubilization: Physicochemical Characterization and Toxicity against Insecticide-Resistant Cimex lectularius. Molecules 2020, 25, 2290. [CrossRef]

11. Lucia, A.; Guzmán, E.; Rubio, R.G.; Ortega, F. Enhanced solubilization of an insect juvenile hormone (JH) mimetic (piryproxyfen) using eugenol in water nanoemulsions stabilized by a triblock copolymer of poly(ethylenglycol) and poly(propilenglycol). Colloids Surf. A 2020, 606, 125513. [CrossRef]

12. Guzmán, E.; Fernández-Peña, L.; Rossi, L.; Bouvier, M.; Ortega, F.; Rubio, R.G. Nanoemulsions for the Encapsulation of Hydrophobic Actives. Cosmetics 2021, 8, 45. [CrossRef]

13. Mateos-Maroto, A.; Abelenda-Núñez, I.; Ortega, F.; Rubio, R.G.; Guzmán, E. Polyelectrolyte Multilayers on Soft Colloidal Nanosurfaces: A New Life for the Layer-By-Layer Method. Polymers 2021, 13, 1221. [CrossRef] [PubMed]

14. Vieira, M.V.; Pastrana, L.M.; Fuciños, P. Microalgae Encapsulation Systems for Food, Pharmaceutical and Cosmetics Applications. Mar. Drugs 2020, 18, 644. [CrossRef] [PubMed]

15. Kuang, S.S.; Oliveira, J.C.; Crean, A.M. Microencapsulation as a Tool for Incorporating Bioactive Ingredients into Food. Crit. Rev. Food Sci. Nutr. 2010, 50, 951-968. [CrossRef] [PubMed]

16. Mamusa, M.; Resta, C.; Sofroniou, C.; Baglioni, P. Encapsulation of volatile compounds in liquid media: Fragrances, flavors, and essential oils in commercial formulations. Adv. Colloid Interface Sci. 2021, 298, 102544. [CrossRef] 
17. Sun, Y.; Shi, J.; Cai, Z.; Wu, Y.; Li, W.; Huo, Q.; Jiang, Z. Mussel-inspired capsules toward reaction-triggered cargo release. Mater. Chem. Front. 2021, 5, 792-798. [CrossRef]

18. Le, T.N.Q.; Tran, N.N.; Escribà-Gelonch, M.; Serra, C.A.; Fisk, I.; McClements, D.J.; Hessel, V. Microfluidic encapsulation for controlled release and its potential for nanofertilisers. Chem. Soc. Rev. 2021, 50, 11979-12012. [CrossRef] [PubMed]

19. Rahdar, A.; Sargazi, S.; Barani, M.; Shahraki, S.; Sabir, F.; Aboudzadeh, M.A. Lignin-Stabilized Doxorubicin Microemulsions: Synthesis, Physical Characterization, and In Vitro Assessments. Polymers 2021, 13, 641. [CrossRef]

20. Aboudzadeh, M.A.; Mehravar, E.; Fernandez, M.; Lezama, L.; Tomovska, R. Low-Energy Encapsulation of $\alpha$-Tocopherol Using Fully Food Grade Oil-in-Water Microemulsions. ACS Omega 2018, 3, 10999-11008. [CrossRef]

21. Mohammed, A.N.; Ishwarya, S.P.; Nisha, P. Nanoemulsion Versus Microemulsion Systems for the Encapsulation of Beetroot Extract: Comparison of Physicochemical Characteristics and Betalain Stability. Food Bioprocess. Technol. 2021, 14, 133-150. [CrossRef]

22. Lo, J.-T.; Lee, T.-M.; Chen, B.-H. Nonionic Microemulsions as Solubilizers of Hydrophobic Drugs: Solubilization of Paclitaxel. Materials 2016, 9, 761. [CrossRef]

23. Ashaolu, T.J. Nanoemulsions for health, food, and cosmetics: A review. Environ. Chem. Lett. 2021, 19, 3381-3395. [CrossRef]

24. McClements, D.J. Emulsion Design to Improve the Delivery of Functional Lipophilic Components. Ann. Rev. Food Sci. Technol. 2010, 1, 241-269. [CrossRef] [PubMed]

25. Spada, F.; Barnes, T.M.; Greive, K.A. Skin hydration is significantly increased by a cream formulated to mimic the skin's own natural moisturizing systems. Clin. Cosmet. Investig. Dermatol. 2018, 11, 491-497. [CrossRef]

26. Simonazzi, A.; Cid, A.G.; Villegas, M.; Romero, A.I.; Palma, S.D.; Bermúdez, J.M. Nanotechnology Applications in Drug Controlled Release. In Drug Targeting and Stimuli Sensitive Drug Delivery Systems; Grumezescu, A.M., Ed.; William Andrew Publishing: Norwich, NY, USA, 2018; pp. 81-116.

27. Venkataramani, D.; Tsulaia, A.; Amin, S. Fundamentals and applications of particle stabilized emulsions in cosmetic formulations. Adv. Colloid Interface Sci. 2020, 283, 102234. [CrossRef] [PubMed]

28. Patzelt, A.; Richter, H.; Dähne, L.; Walden, P.; Wiesmüller, K.-H.; Wank, U.; Sterry, W.; Lademann, J. Influence of the Vehicle on the Penetration of Particles into Hair Follicles. Pharmaceutics 2011, 3, 307-314. [CrossRef] [PubMed]

29. Sedyakina, N.E.; Krivoshchepov, A.F.; Zasypko, A.Y.; Demchenko, A.G.; Rozofarov, A.L.; Kuryakov, V.N.; Feldman, N.B.; Lutsenko, S.V. Formulation, drug release features and in vitro cytotoxic evaluation of nonionic mixed surfactant stabilized water-in-oil microemulsion loaded with doxorubicin. Mendeleev Commun. 2019, 29, 320-322. [CrossRef]

30. Lu, B.; Bo, Y.; Yi, M.; Wang, Z.; Zhang, J.; Zhu, Z.; Zhao, Y.; Zhang, J. Enhancing the Solubility and Transdermal Delivery of Drugs Using Ionic Liquid-In-Oil Microemulsions. Adv. Funct. Mat. 2021, 31, 2102794. [CrossRef]

31. Sargazi, S.; Hajinezhad, M.R.; Barani, M.; Rahdar, A.; Shahraki, S.; Karimi, P.; Cucchiarini, M.; Khatami, M.; Pandey, S. Synthesis, characterization, toxicity and morphology assessments of newly prepared microemulsion systems for delivery of valproic acid. $J$. Mol. Liq. 2021, 338, 116625. [CrossRef]

32. Hasanein, P.; Rahdar, A.; Barani, M.; Baino, F.; Yari, S. Oil-In-Water Microemulsion Encapsulation of Antagonist Drugs Prevents Renal Ischemia-Reperfusion Injury in Rats. Appl. Sci. 2021, 11, 1264. [CrossRef]

33. Fernández-Peña, L.; Gutiérrez-Muro, S.; Guzmán, E.; Lucia, A.; Ortega, F.; Rubio, R.G. Oil-In-Water Microemulsions for Thymol Solubilization. Colloids Interfaces 2019, 3, 64. [CrossRef]

34. Aum, P.T.P.; Gurgel Aum, Y.K.P.; de Andrade Araújo, E.; de Almeida Cavalcante, L.; Nobre Nunes da Silva, D.; Regis dos Santos Lucas, C.; de Castro Dantas, T.N. Evaluation of oil-in-water microemulsion base ethoxylated surfactant under acid conditions. Fuel 2021, 290, 120045. [CrossRef]

35. Vo, T.-V.; Chou, Y.-Y.; Chen, B.-H. Preparation of Microemulsion from an Alkyl Polyglycoside Surfactant and Tea Tree Oil. Molecules 2021, 26, 1971. [CrossRef] [PubMed]

36. Kahraman, E.; Kaykın, M.; Şahin Bektay, H.; Güngör, S. Recent Advances on Topical Application of Ceramides to Restore Barrier Function of Skin. Cosmetics 2019, 6, 52. [CrossRef]

37. Li, Q.; Fang, H.; Dang, E.; Wang, G. The role of ceramides in skin homeostasis and inflammatory skin diseases. J. Dermatol. Sci. 2020, 97, 2-8. [CrossRef]

38. Alonso, A.; Goñi, F.M. The Physical Properties of Ceramides in Membranes. Annu. Rev. Biophys. 2018, 47, 633-654. [CrossRef] [PubMed]

39. Siavashi, R.; Phaterpekar, T.; Leung, S.S.W.; Alonso, A.; Goñi, F.M.; Thewalt, J.L. Lamellar Phases Composed of Phospholipid Cholesterol, and Ceramide, as Studied by (2)H NMR. Biophys. J. 2019, 117, 296-306. [CrossRef]

40. Pettus, B.J.; Chalfant, C.E.; Hannun, Y.A. Ceramide in apoptosis: An overview and current perspectives. BIochim. Biophys. Acta. Mol. Cell Biol. Lipids 2002, 1585, 114-125. [CrossRef]

41. Turpin-Nolan, S.M.; Brüning, J.C. The role of ceramides in metabolic disorders: When size and localization matters. Nat. Rev. Endocrinol. 2020, 16, 224-233. [CrossRef]

42. Saddoughi, S.A.; Song, P.; Ogretmen, B. Roles of bioactive sphingolipids in cancer biology and therapeutics. Subcell. Biochem. 2008, 49, 413-440. [CrossRef]

43. Hannun, Y.A.; Obeid, L.M. The Ceramide-centric universe of lipid-mediated cell regulation: Stress encounters of the lipid kind. J. Biol. Chem. 2002, 277, 25847-25850. [CrossRef] [PubMed] 
44. Sheridan, M.; Ogretmen, B. The Role of Ceramide Metabolism and Signaling in the Regulation of Mitophagy and Cancer Therapy. Cancers 2021, 13, 2475. [CrossRef]

45. Senchenkov, A.; Litvak, D.A.; Cabot, M.C. Targeting ceramide metabolism-a strategy for overcoming drug resistance. J. Natl. Cancer Inst. 2001, 93, 347-357. [CrossRef] [PubMed]

46. Kim, K.P.; Shin, K.-O.; Park, K.; Yun, H.J.; Mann, S.; Lee, Y.M.; Cho, Y. Vitamin C Stimulates Epidermal Ceramide Production by Regulating Its Metabolic Enzymes. Biomol. Ther. 2015, 23, 525-530. [CrossRef]

47. Barth, B.M.; Cabot, M.C.; Kester, M. Ceramide-based therapeutics for the treatment of cancer. Anti-Cancer Agents Med. Chem. 2011, 11, 911-919. [CrossRef] [PubMed]

48. Li, F.; Zhang, N. Ceramide: Therapeutic Potential in Combination Therapy for Cancer Treatment. Curr. Drug Metab. 2015, 17, 37-51. [CrossRef] [PubMed]

49. Ma, Y.Y.; Mou, X.Z.; Ding, Y.H.; Zou, H.; Huang, D.S. Delivery systems of ceramide in targeted cancer therapy: Ceramide alone or in combination with other anti-tumor agents. Expert Opin. Drug Deliv. 2016, 13, 1397-1406. [CrossRef] [PubMed]

50. Santos, A.C.; Pereira-Silva, M.; Guerra, C.; Costa, D.; Peixoto, D.; Pereira, I.; Pita, I.; Ribeiro, A.J.; Veiga, F. Topical MinoxidilLoaded Nanotechnology Strategies for Alopecia. Cosmetics 2020, 7, 21. [CrossRef]

51. Dhule, S.S.; Penfornis, P.; He, J.; Harris, M.R.; Terry, T.; John, V.; Pochampally, R. The combined effect of encapsulating curcumin and C6 ceramide in liposomal nanoparticles against osteosarcoma. Mol. Pharm. 2014, 11, 417-427. [CrossRef]

52. Cruz, A.F.; Caleiras, M.B.; Fonseca, N.A.; Gonçalves, N.; Mendes, V.M.; Sampaio, S.F.; Moura, V.; Melo, J.B.; Almeida, R.D.; Manadas, B.; et al. The Enhanced Efficacy of Intracellular Delivery of Doxorubicin/C6-Ceramide Combination Mediated by the F3 Peptide/Nucleolin System Is Supported by the Downregulation of the PI3K/Akt Pathway. Cancers 2021, 13, 3052. [CrossRef]

53. Vovesná, A.; Zhigunov, A.; Balouch, M.; Zbytovská, J. Ceramide liposomes for skin barrier recovery: A novel formulation based on natural skin lipids. Int. J. Pharm. 2021, 596, 120264. [CrossRef]

54. Jung, S.-M.; Yoon, G.H.; Lee, H.C.; Jung, M.H.; Yu, S.I.; Yeon, S.J.; Min, S.K.; Kwon, Y.S.; Hwang, J.H.; Shin, H.S. Thermodynamic Insights and Conceptual Design of Skin-Sensitive Chitosan Coated Ceramide/PLGA Nanodrug for Regeneration of Stratum Corneum on Atopic Dermatitis. Sci. Rep. 2015, 5, 18089. [CrossRef] [PubMed]

55. Deli, G.; Hatziantoniou, S.; Nikas, Y.; Demetzos, C. Solid lipid nanoparticles and nanoemulsions containing ceramides: Preparation and physicochemical characterization. J. Liposome Res. 2009, 19, 180-188. [CrossRef] [PubMed]

56. Yilmaz, E.; Borchert, H.-H. Effect of lipid-containing, positively charged nanoemulsions on skin hydration, elasticity and erythema-An in vivo study. Int. J. Pharm. 2006, 307, 232-238. [CrossRef]

57. Tessema, E.N.; Gebre-Mariam, T.; Paulos, G.; Wohlrab, J.; Neubert, R.H.H. Delivery of oat-derived phytoceramides into the stratum corneum of the skin using nanocarriers: Formulation, characterization and in vitro and ex-vivo penetration studies. Eur. J. Pharm. Biopharm. 2018, 127, 260-269. [CrossRef]

58. Patzelt, A.; Lademann, J.; Richter, H.; Darvin, M.E.; Schanzer, S.; Thiede, G.; Sterry, W.; Vergou, T.; Hauser, M. In vivo investigations on the penetration of various oils and their influence on the skin barrier. Ski. Res. Technol. 2012, 18, 364-369. [CrossRef]

59. Khan, H.M.; Naveed, A.; Rasul, A.; Rashid, S.; Mustafa, R.; Khan, B.; Murtaza, G. In vivo Evaluation of a Cosmetic Emulsion Containing Soybean Extract for Anti-Aging. Trop. J. Pharm. Res. 2014, 13, 1401-1406. [CrossRef]

60. Boelsma, E.; Tanojo, H.; Boddé, H.E.; Ponec, M. Assessment of the potential irritancy of oleic acid on human skin: Evaluation in vitro and in vivo. Toxicol. Vitr. 1996, 10, 729-742. [CrossRef]

61. Miguel-Hernández, A.S.; Miguel-Rodríguez, A.S.; Martín-Armentia, B.; Martín-Armentia, S.; Armentia-Medina, A.; Lozano-Estevan, C.; Iglesias-Peinado, I. Implications of Allergic Reactions to Soybean Oil. J. Allergy Disord. Ther. 2018, 4, 008. [CrossRef]

62. Bhargava, H.N. The Present Status of Formulation of Cosmetic Emulsions. Drug Dev. Ind. Pharm. 1987, 13, 2363-2387. [CrossRef]

63. Llamas, S.; Guzmán, E.; Baghdadli, N.; Ortega, F.; Cazeneuve, C.; Rubio, R.G.; Luengo, G.S. Adsorption of poly(diallyldimethylammonium chloride)—Sodium methyl-cocoyl-taurate complexes onto solid surfaces. Colloids Surf. A 2016, 505, 150-157. [CrossRef]

64. Guzmán, E.; Llamas, S.; Fernández-Peña, L.; Léonforte, F.; Baghdadli, N.; Cazeneuve, C.; Ortega, F.; Rubio, R.G.; Luengo, G.S. Effect of a natural amphoteric surfactant in the bulk and adsorption behavior of polyelectrolyte-surfactant mixtures. Colloids Surf. A 2020, 585, 124178. [CrossRef]

65. Hernández-Rivas, M.; Guzmán, E.; Fernández-Peña, L.; Akanno, A.; Greaves, A.; Léonforte, F.; Ortega, F.; Rubio, R.G.; Luengo, G.S. Deposition of Synthetic and Bio-Based Polycations onto Negatively Charged Solid Surfaces: Effect of the Polymer Cationicity, Ionic Strength, and the Addition of an Anionic Surfactant. Colloids Interfaces 2020, 4, 33. [CrossRef]

66. Mateos, H.; Valentini, A.; Robles, E.; Brooker, A.; Cioffi, N.; Palazzo, G. Measurement of the zeta-potential of solid surfaces through Laser Doppler Electrophoresis of colloid tracer in a dip-cell: Survey of the effect of ionic strength, $\mathrm{pH}$, tracer chemical nature and size. Colloids Surf. A 2019, 576, 82-90. [CrossRef]

67. Mateos, H.; Valentini, A.; Lopez, F.; Palazzo, G. Surfactant Interactions with Protein-Coated Surfaces: Comparison between Colloidal and Macroscopically Flat Surfaces. Biomimetics 2020, 5, 31. [CrossRef]

68. Mateos, H.; Valentini, A.; Colafemmina, G.; Murgia, S.; Robles, E.; Brooker, A.; Palazzo, G. Binding isotherms of surfactants used in detergent formulations to bovine serum albumin. Colloids Surf. A 2020, 598, 124801. [CrossRef] 
69. Lucia, A.; Toloza, A.C.; Fanucce, M.; Fernández-Peña, L.; Ortega, F.; Rubio, R.G.; Coviella, C.; Guzmán, E. Nanoemulsions based on thymol-eugenol mixtures: Characterization, stability and larvicidal activity against Aedes aegypti. Bull. Insectol. 2020, 73, 153-160.

70. Berne, B.J.; Pecora, R. Dynamic Light Scattering: With Applications to Chemistry, Biology, and Physics; Dover Publications Inc.: Mineola, NY, USA, 2003.

71. Sabale, V.; Vora, S. Formulation and evaluation of microemulsion-based hydrogel for topical delivery. Int. J. Pharm. Investig 2012, 2, 140-149. [CrossRef]

72. Malakar, J.; Sen, S.O.; Nayak, A.K.; Sen, K.K. Development and evaluation of microemulsions for transdermal delivery of insulin. ISRN Pharm. 2011, 2011, 780150. [CrossRef]

73. Liu, M.; Cao, X.-1.; Zhu, Y.-w.; Tong, Y.; Zhang, L.; Zhang, L.; Zhao, S. Effect of Oleic Acid on the Dynamic Interfacial Tensions of Surfactant Solutions. Energy Fuels 2018, 32, 5868-5876. [CrossRef]

74. Sun, H.-Q.; Guo, Z.-Y.; Cao, X.-L.; Zhu, Y.-W.; Pan, B.-L.; Liu, M.; Zhang, L.; Zhang, L. Interfacial interactions between oleic acid and betaine molecules at decane-water interface: A study of dilational rheology. J. Mol. Liq. 2020, 316, 113784. [CrossRef]

75. Kwon, Y.; Jo, S.; Na, H.; Kim, S.; Kim, M.-J.; Lee, J. Effects of 1,2-dioleoyl-sn-glycero-3-phosphocholine on moisture content and oxidative stability in soybean oil-water system at different interfaces. Food Sci. Biotechnol. 2019, 29, 479-486. [CrossRef]

76. Tolman, R.C. The Effect of Droplet Size on Surface Tension. J. Chem. Phys. 1949, 17, 333-337. [CrossRef]

77. Djekic, L.; Primorac, M.; Filipic, S.; Agbaba, D. Investigation of surfactant/cosurfactant synergism impact on ibuprofen solubilization capacity and drug release characteristics of nonionic microemulsions. Int. J. Pharm. 2012, 433, 25-33. [CrossRef]

78. Callender, S.P.; Mathews, J.A.; Kobernyk, K.; Wettig, S.D. Microemulsion utility in pharmaceuticals: Implications for multi-drug delivery. Int. J. Pharm. 2017, 526, 425-442. [CrossRef]

79. Rosen, M.J.; Kunjappu, J.T. Emulsification of Surfactants. In Surfactants and Interfacial Phenomena; Rosen, M.J., Kunjappu, J.T., Eds.; John Wiley \& Sons, Inc.: Hoboken, NJ, USA, 2012; pp. 336-366.

80. Chung, H.; Kim, T.W.; Kwon, M.; Kwon, I.C.; Jeong, S.Y. Oil components modulate physical characteristics and function of the natural oil emulsions as drug or gene delivery system. J. Control. Release 2001, 71, 339-350. [CrossRef]

81. Ashara, K.C.; Paun, J.S.; Soniwala, M.M.; Chavda, J.R.; Mendapara, V.P.; Mori, N.M. Microemulgel: An overwhelming approach to improve therapeutic action of drug moiety. Saudi Pharm. J. 2016, 24, 452-457. [CrossRef] 